\title{
Experiments on clinical observation and judgement in the assessment of depression: profiled videotapes and Judgement Analysis
}

\author{
P. BECH, A. HAABER, C. R. B. JOYCE \\ AND THE DANISH UNIVERSITY ANTI-DEPRESSANT GROUP (DUAG) ${ }^{2}$
}

From the Psykiatrisk Afdeling, Frederiksborg Amts Centralsygehus, Hillerod, Denmark

SYNOPSIS Variations within and between observer-judges reduce the accuracy of clinical research. Judgement Analysis allows strategies to be developed and applied which reduce variation in judgement. The prediction that the removal of important sources of error variance by this means would reduce the likelihood of committing a Type 2 Error was supported by the application of Judgement Analysis to assessments by 15 psychiatrists of 92 patients in a clinical trial of 2 antidepressive treatments. The statistical significance of differences between the effect of the treatments on the severity of depression was increased, and significant differences appeared earlier. Ten stimulated patient profiles were also converted into narrative case histories, enacted by experienced psychiatrists or psychologists and videotaped. The participants' judgements of the overall severity of the depression were in good agreement with those they had made on the original cases. Videotapes so prepared help training to reduce variation in observation, just as Judgement Analysis can lead to reductions in the variation of judgement.

\section{INTRODUCTION}

In medicine, as in many activities, two main tasks are to observe and to make judgements on the basis of the observations. Observation can often be taken over by apparatus(electrocardiographic, spirometric, haematologic etc.) or standardized in other ways. In psychiatry, however, much information is still collected by direct human observation, whether or not recorded quantitatively with the aid of rating-scales. These observations are then combined to arrive at diagnoses, choice of treatment, assessment of outcome, etc. Often, observations themselves contain a large element of judgement, and the two tasks therefore appear inextricably entwined.

\footnotetext{
1 Address for correspondence: Dr C. R. B. Joyce, Project Innovation Group, Medical Department, Ciba-Geigy AG, 4002 Basel, Switzerland.

"Members: Drs J. Aagaard, J. Andersen, R. Bang-Olsen, M. Bjerre, S. Bøjholm, P. Christensen, A. Gjerris, L. F. Gram, H. Hansen, W. Hansen, L. Hansted, E. H. Hestrup, E. Jensen, P. W. Jepsen, L. Jorgensen, M. Kastrup, B. Kijne, P. Kragh-Sørensen, C. B. Kristensen, D. Loldrup, K. W. Maarbjerg, O. F. Madsen, E. B. Østergaard, K. R. Pedersen, O. L. Pedersen, O. J. Rafaelsen, S. Rasmussen, N. Reisby, J. Schmid, F. Sevaj, K. Sørensen, E. Thogersen, H. Y. Thomsen, P. Vestergaard, F. Zierau.
}

In consequence, accuracy and consistency are lost, and the use of the information obtained is impaired. Because of the resulting 'noise', the rate of Type 2 Errors $^{3}$ will increase (Stewart et al. 1975; Joyce, 1984) and patient treatments will, in consequence, be less accurately chosen. This kind of error is more likely to arise when, as is usual in clinical trials, several investigators are involved. (Even in single centre trials, it is common for more than one investigator to be involved, not always explicitly.)

Pre-clinical as well as clinical tests of new drugs are frequently carried out on samples that are too small to allow either Type $1^{4}$ or Type 2 Error to be avoided with a high degree of probability (Freiman et al. 1978). The avoidance of Type 1 Error is normally given priority indeed, the Type 2 Error is seldom stated explicitly (Vere, 1984) - so an unknown, but perhaps high, proportion of useful treatments are incorrectly evaluated because of Type 2

3 Type 2 Error: failure to detect a true difference between treatments (false negative).

4 Type I Error: acceptance of a difference between treatments as true when it is in fact false (false positive). See Mainland (1963) for a full discussion of these well-known problems. 


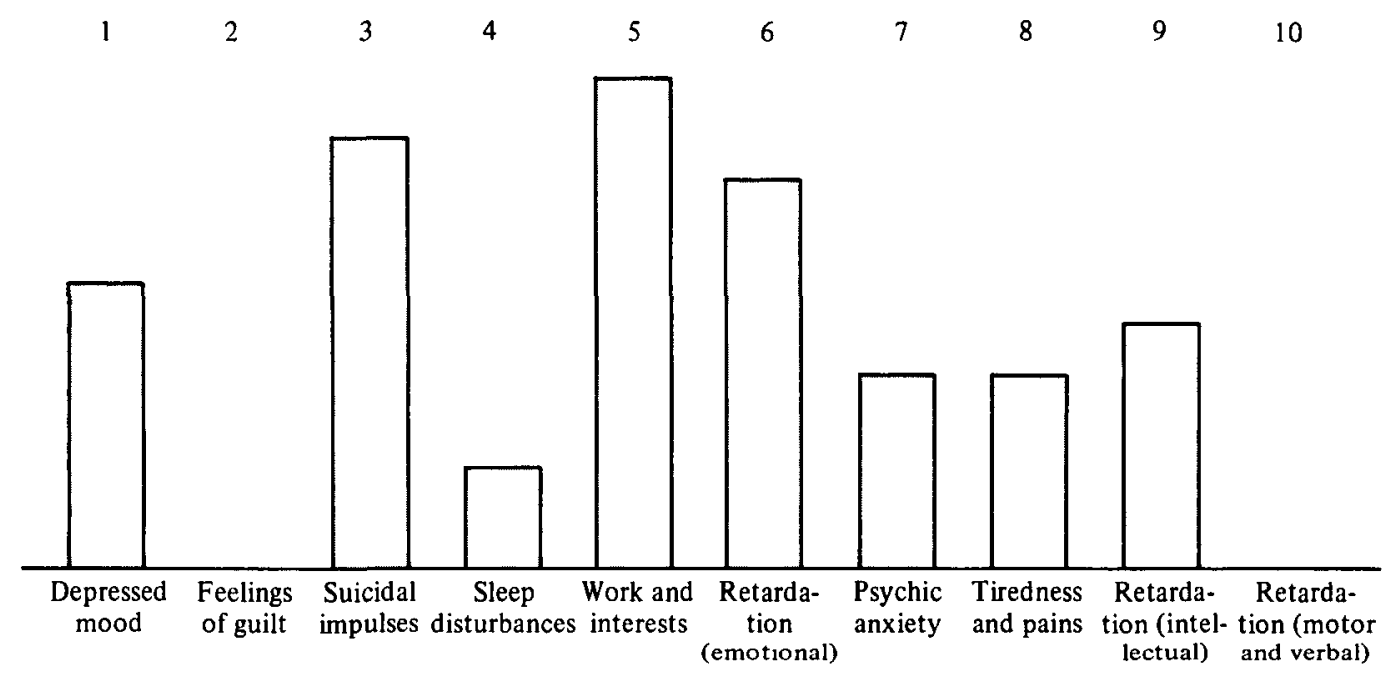

Please indicate by an ' $X$ ' your estimate of the severity of the depressive state:

No depression
$\begin{gathered}\text { Among the most extremely } \\ \text { depressed patients }\end{gathered}$

Fig. I. Example of simulated case record (MES profile) for Case No. 14.

Errors. It should be noted that although a Type 2 Error may, in theory, cause either of the treatments being compared to be dropped, in practice it is more likely that a new treatment will be discarded, whether the comparison is with a placebo or a standard.

As a first step in attacking this problem, by reducing variation due to observation and judgement, it is desirable to separate them, as far as possible, for separate study. There are various means for doing this. Fisch and his colleagues have used a form of multivariate regression analysis (Hammond, 1975) to study the judgement of physicians (Fisch et al. 1981, 1982). This makes explicit the bases of such differences between judges (as well as the almost invariably neglected variation between occasions within the same judge), allows them to be resolved, and permits the observations to be judged according to virtually any strategy desired. The purpose of the present study is to demonstrate that the method, by removing variation arising from judgement 'error' in regard to disease severity, allows the size of differences between treatments in a real clinical trial to be more accurately determined.

\section{METHODS AND PROCEDURE}

Judgement Analysis (JA) has been fully described by Hammond (1975), Fisch et al. (1981) and others. Important differences from these accounts are described below, but the basic procedure consists in presenting the judge with a series (frequently 50 ) of either real or simulated 'cases', each of which is represented as a set of numerical or pictorial scores on a number (usually 10 or fewer) of items previously agreed to contain most, or all, of the information required to make an appropriate judgement (diagnosis, assessment of progress, choice of treatment, etc.) about the case. The resulting judgements are submitted to a form of multiple regression analysis (JA) to determine the weights applied to each item of information by the individual in reaching a judgement.

\section{Simulated cases}

Patients with depressive states were simulated with numbers (generated by a standard method) to represent scores on the items contained in the Melancholia Scale (MES) (Bech \& Rafaelsen, 1980; Bech, 1981; Bech et al. 1983). The MES 
consists of 11 items, selected from the Hamilton Depression Scale (HDS) (Hamilton, 1960) and the Cronholm-Ottosson Scale (Cronholm \& Ottosson, 1960) for their validity in evaluating the severity of depressive states. In the present study two MES items (motor and verbal retardation) were combined into one, because verbal retardation would have interfered with the preparation and usefulness of the video representations.

Fifty cases were each represented by a sheet containing a set of scores for the 10 MES items as vertical bars, the heights of which were proportional to numbers generated by the computer (Fig. 1 illustrates the display for Case No. 14). Nine were chosen at random for duplication, to provide a check on withinobserver reliability. This number of cases and replicates has repeatedly been found adequate to model judgemental policies and to estimate individual reliability. The task of each psychiatrist was to judge the severity of depression on a $10 \mathrm{~cm}$ visual analogue scale (VAS), labelled 'No depression' at the left-hand end, and 'Among the most extremely depressed patients' at the right.

\section{Videotape cases}

The scores of the duplicate simulated cases plus one other were converted into narrative case histories by one of us (P.B.). One case was enacted by each of 8 experienced psychiatrists and 2 experienced clinical psychologists in such a way as to represent a patient undergoing a clinical interview with P.B. Each recording lasted for 5-8 minutes. A narrative account of the interview for Case No. 14 (compare Fig. 1) is given in the Appendix.

\section{Psychiatrists}

Twenty-eight psychiatrists, all members of the Danish University Anti-depressant Group (DUAG) and working in the Departments of Psychiatry of 4 hospitals (Rigshospitalet, Copenhagen; Frederiksborg General Hospital, Hillerød; Odense Hospital, Odense; Aarhus University, Aarhus), were invited to participate in a comparative clinical trial (see below). They are described in Table 1 in terms of years of practice in psychiatry, sex, treatment orientation, attitude to the use of rating scales, experience with the MES, Hamilton Depression Scale
(HDS) or Newcastle Scales. Fifteen took part in the clinical trial. The remaining 13 psychiatrists were working in the same 4 departments and had similar professional status, etc., but admitted no patients to the trial. Information about the latter (including their judgemental policies) is presented as evidence of the representativeness of the sample of those participating in the clinical trial. The 'expert' judgements of P.B. and of another senior colleague (Professor O. J. Rafaelsen) were obtained separately in a similar way.

\section{Presentation sessions}

On the first occasion the participants, who had previously been contacted informally to secure their cooperation, were brought together in their respective hospitals for about 1 hour. P.B. outlined the intentions and the methods to be used, answered questions and handed out questionnaires about training experience, etc. Each psychiatrist completed a record form to specify the importance which he or she considered each item of the MES should be given when estimating the severity of depressive illness, and when selecting a treatment for depression. Each then received a booklet containing the 50 simulated case profiles in standard order, for assessment at home. Judgements were made at the physician's own preferred pace; no record of time taken was required.

The case information and judgements were entered into the POLICY programme (Hammond et al. 1975) to determine the multivariate regression of judgements on the MES items and the 30 judgemental 'policies' (the weights used when each participant combined the information from the 10 items in arriving at a judgement of severity) were extracted.

On the second occasion the videotapes were shown by P.B. and A.H. to the participants of two centres at a time (Copenhagen and Hillerød; Aarhus and Odense). Participants were asked to score each videotape case on the items of the MES, before making the judgement of severity in the same way as they had for the simulated cases.

\section{The clinical trial}

Fifteen psychiatrists contributed patients to a double-blind, 35-day between-group comparison of clomipramine (Anafranil ${ }^{\oplus}$ Geigy) and citalopram in the treatment of 92 hospitalized patients 
Table 1. Information on place of work, sex, experience, attitudes of participating psychiatrists

\begin{tabular}{|c|c|c|c|c|c|c|c|c|}
\hline \multirow[b]{2}{*}{ Doctor } & \multirow[b]{2}{*}{ Department } & \multirow{2}{*}{$\begin{array}{l}\text { Participant } \\
\text { in clinical } \\
\text { trial }\end{array}$} & \multirow[b]{2}{*}{ Sex } & \multirow[b]{2}{*}{$\begin{array}{c}\text { Years in } \\
\text { psychiatry }\end{array}$} & \multicolumn{2}{|c|}{ Experience with $\dagger$} & \multirow[b]{2}{*}{$\begin{array}{l}\text { Attitude to } \\
\text { rating scales }\end{array}$} & \multirow{2}{*}{$\begin{array}{c}\text { Balance of } \\
\text { preference } \\
\text { for } \\
\text { treatment\$ }\end{array}$} \\
\hline & & & & & $\begin{array}{c}\text { MES } \\
\text { (HDS) }\end{array}$ & $\begin{array}{c}\text { Newcastle } \\
\text { Scales }\end{array}$ & & \\
\hline 101 & Copenhagen & + & $\mathbf{M}$ & 10 & 3 & 3 & + & 72 \\
\hline 102 & Copenhagen & + & $\mathrm{F}$ & 5 & 3 & 3 & + & 82 \\
\hline 103 & Copenhagen & - & $\mathrm{F}$ & 8 & 2 & 2 & - & 60 \\
\hline 104 & Copenhagen & - & $\mathbf{M}$ & 9 & 2 & 2 & + & 39 \\
\hline 105 & Odense & + & $\mathbf{M}$ & 7 & 3 & 3 & + & 76 \\
\hline 106 & Odense & + & $\mathbf{M}$ & 6 & 3 & 3 & + & 49 \\
\hline 107 & Odense & + & $\mathbf{M}$ & 7 & 3 & 3 & + & 50 \\
\hline 108 & Odense & - & $\mathbf{M}$ & 4 & 2 & 2 & + & 53 \\
\hline 109 & Odense & - & $\mathbf{M}$ & 4 & 0 & 0 & + & 26 \\
\hline 110 & Odense & - & $\mathbf{M}$ & 5 & 0 & 0 & + & 50 \\
\hline 111 & Hillerod & + & $\mathbf{F}$ & 4 & 3 & 3 & + & 57 \\
\hline 112 & Hillerød & + & $\mathbf{M}$ & 8 & 3 & 3 & + & 67 \\
\hline 113 & Hillered & + & $\mathbf{M}$ & 4 & 3 & 3 & + & 53 \\
\hline 114 & Hillerad & + & $\mathbf{M}$ & 5 & 3 & 3 & + & 26 \\
\hline 115 & Hillerad & + & $\mathbf{M}$ & 3 & 3 & 3 & + & 77 \\
\hline 116 & Hillerød & - & $\mathbf{F}$ & 9 & 2 & $\mathbf{0}$ & $?$ & 72 \\
\hline 117 & Hillerød & - & $F$ & 4 & 3 & 3 & + & 78 \\
\hline 118 & Hillerød & - & $\mathbf{M}$ & 7 & 2 & 2 & + & 50 \\
\hline 120 & Hillerød & - & $\mathbf{M}$ & 5 & 2 & 2 & $?$ & 53 \\
\hline 131 & Hillerod & - & $\mathrm{F}$ & 5 & 2 & 2 & - & 74 \\
\hline 132 & Hillerød & - & $\mathrm{F}$ & 4 & 3 & 3 & + & 50 \\
\hline 122 & Aarhus & + & $\mathbf{M}$ & 4 & 3 & 0 & + & 37 \\
\hline 124 & Aarhus & + & $F$ & 5 & 2 & 1 & + & 50 \\
\hline 126 & Aarhus & - & $\mathbf{M}$ & 4 & 1 & 0 & - & 50 \\
\hline 127 & Aarhus & + & $\mathbf{M}$ & 7 & 3 & 1 & - & 41 \\
\hline 128 & Aarhus & + & $\mathbf{F}$ & 5 & 2 & 2 & + & 51 \\
\hline 129 & Aarhus & - & $\mathrm{M}$ & 3 & 2 & 1 & + & 50 \\
\hline 130 & Aarhus & + & $\mathbf{M}$ & 5 & 2 & 0 & + & 92 \\
\hline
\end{tabular}

$\dagger 0=$ none; $3=$ great.

$\ddagger-=$ little value; $+=$ high value; $?=$ doubtful.

$\S 0=$ psychotherapy only; $100=$ pharmacotherapy only.

suffering from depressive disorders. The methodology and results were fully described at the CINPSymposium on 5-HT Re-uptake Inhibitors, held in Florence in June 1984 (Bech, 1984).

The judgement policies previously obtained were applied to the trial observations on the 10 items of the modified MES to obtain the sets of computed judgements described below. The appropriate derived weight was applied to each item score and the products were summed to give the predicted judgement for the case.

\section{RESULTS}

\section{Differences between psychiatrists}

The place of work, sex, years of experience in psychiatry, experience with and attitude to rating scales and various forms of therapy are summarized for those who did $(N=15)$ and did not $(N=13)$ participate in the trial (Table 1). Participants and non-participants were about equally represented in all centres except Aarhus. There were 9 women and 19 men. Attitudes to rating scales were positive (22/28), and experience with rating scales was greater in those contributing patients to the clinical trial; it was not related to years in psychiatry.

Psychiatrists in Copenhagen had had more $(8.0)$ and in Aarhus (4.7) less than the mean experience $(5.5$ years). As measured on a $10 \mathrm{~cm}$ visual analogue scale $(0=$ maximal preference for psychotherapy; $100=$ maximal preference for pharmacotherapy), participants perhaps had a slightly more positive attitude towards the use of pharmacotherapy than non-participants.

\section{Differences in observations and judgements}

Correlations between the original computersimulated mean total scores on the MES items 
Table 2. Correlations between measures for 10 replicate patients

\begin{tabular}{llll}
\hline & VMES & \multicolumn{1}{c}{ SS } & \multicolumn{1}{c}{ vS } \\
\hline SMES & $0.78^{* *}$ & $0.73^{*}$ & $0.71^{*}$ \\
VMES & - & $0.68^{*}$ & $0.98^{* * *}$ \\
SS & - & - & $0.62^{*}$ \\
\hline
\end{tabular}

SMES: simulated cases - total MES item score (computer generated). VMES: video cases - mean total MES ( $N=28$ scores).

SS: simulated cases - severity ( $N=28$ judgements).

VS: video cases - severity ( $N=28$ judgements).

$* P<0.05 ; * * P<0.01$; *** $P<0.001$

(SMES), the mean total MES scores given the 10 video cases by the 28 psychiatrists (VMES), and the corresponding severity judgements for the simulated (SS) and video cases (VS) are presented in Table 2. Although all correlation coefficients were statistically significant, only one (VS/VMES) accounted for more than $61 \%$ of the variance. Inter-observer reliability, as estimated by kappa (Bartko \& Carpenter, 1976), was low $(0.38,0.57,0.58)$, although significant $(P<0.01)$, for the 3 variables where such a measure was possible (VMES, SS, VS: excluding the original set of standard HMES scores generated by the computer).

\section{Policy differences within and between judges}

The weights which the psychiatrists considered that they usually attached to each of the $10 \mathrm{MES}$ items (the 'specified' weights) are shown in Table 3 . The average marks of each judge $(\bar{x})$ on the 10 analogue scales representing the specified weights ranged from 39 to 84 (mean 63.2).

The departures of the weights specified from those expected had the judge given equal weight (i.e. $10 \%$ ) to each item are expressed by $\chi^{2}$. The specified weights of only 9 judges departed significantly from equality $\left(\chi^{2}>16.92, \mathrm{df}=9\right.$, $P<0.05$ ). Only 2 (Nos. 112 and 130 ) gave a weight of more than $20 \%$ to a single cue.

The actual weights obtained from multiple regression analysis of the judgements (Table 4)

Table 3. Specified relative weights for 28 investigators using 10 MES cues to severity of depression

\begin{tabular}{|c|c|c|c|c|c|c|c|c|c|c|c|c|}
\hline \multirow[b]{2}{*}{ Psychiatrist } & \multicolumn{10}{|c|}{ Cue } & \multirow[b]{2}{*}{$\chi^{2}$} & \multirow[b]{2}{*}{$\bar{x}$} \\
\hline & 1 & 2 & 3 & 4 & 5 & 6 & 7 & 8 & 9 & 10 & & \\
\hline 101 & 13 & 7 & 12 & 8 & 8 & 13 & 13 & 4 & 13 & 10 & $9 \cdot 3$ & $63 \cdot 1$ \\
\hline 102 & 14 & 16 & 13 & 4 & 4 & 15 & 8 & 3 & 8 & 15 & $24 \cdot 0^{* *}$ & $59 \cdot 1$ \\
\hline 103 & 15 & 14 & 8 & 14 & 15 & 8 & 8 & 4 & 7 & 7 & 14.8 & 65.4 \\
\hline 104 & 17 & 18 & 11 & 11 & 7 & 6 & 3 & 5 & 6 & 16 & $26 \cdot 6^{* *}$ & 44.4 \\
\hline 105 & 12 & 12 & 6 & 6 & 6 & 12 & 12 & 12 & 12 & 12 & 7.6 & $76 \cdot 3$ \\
\hline 106 & 13 & 9 & 9 & 5 & 5 & 16 & 5 & 12 & 9 & 17 & $17 \cdot 6^{*}$ & $52 \cdot 2$ \\
\hline 107 & 11 & 11 & 9 & 9 & 10 & 10 & 8 & 8 & 11 & 11 & 1.4 & 79.9 \\
\hline 108 & 13 & 15 & 7 & 10 & 9 & 10 & 9 & 10 & 7 & 9 & $5 \cdot 5$ & 54.0 \\
\hline 109 & 7 & 13 & 6 & 10 & 5 & 13 & 13 & 10 & 5 & 10 & $10 \cdot 2$ & $48 \cdot 2$ \\
\hline 110 & 9 & 17 & 4 & 9 & 6 & 16 & 3 & 5 & 16 & 16 & $28 \cdot 5 * * *$ & $45 \cdot 5$ \\
\hline 111 & 15 & 8 & 15 & 8 & 4 & 13 & 6 & 9 & 13 & 9 & 13.0 & $61 \cdot 3$ \\
\hline 112 & . 23 & 7 & 19 & 4 & 19 & 6 & 6 & 6 & 5 & 6 & $46 \cdot 5^{* * *}$ & $39 \cdot 3$ \\
\hline 113 & 13 & 13 & 13 & 9 & 7 & 9 & 10 & 8 & 6 & 12 & $6 \cdot 2$ & 63.5 \\
\hline 114 & 6 & 12 & 11 & 11 & 12 & 13 & 3 & 3 & 12 & 16 & $17 \cdot 3^{*}$ & 63.6 \\
\hline 115 & 12 & 11 & 11 & 11 & 7 & 12 & 7 & 5 & 12 & 11 & 5.9 & $79 \cdot 6$ \\
\hline 116 & 12 & 12 & 13 & 7 & 8 & 11 & 7 & 8 & 9 & 13 & 5.4 & 67.6 \\
\hline 117 & 17 & 11 & 10 & 11 & 14 & 7 & 4 & 9 & 10 & 7 & $12 \cdot 2$ & $40 \cdot 9$ \\
\hline 118 & 8 & 12 & 12 & 12 & 8 & 10 & 10 & 7 & 10 & 11 & 3.0 & $81 \cdot 7$ \\
\hline 120 & 14 & 11 & 11 & 7 & 4 & 12 & 8 & 7 & 12 & 12 & 8.8 & $66 \cdot 6$ \\
\hline 122 & 13 & 9 & 13 & 5 & 11 & 11 & 6 & 7 & 12 & 12 & 7.9 & $73 \cdot 0$ \\
\hline 124 & 13 & 11 & 13 & 6 & 12 & 12 & 10 & 4 & 6 & 13 & $10 \cdot 4$ & $71 \cdot 4$ \\
\hline 126 & 14 & 14 & 14 & 7 & 14 & 14 & 7 & 0 & 0 & 14 & $21 \cdot 4^{*}$ & 68.7 \\
\hline 127 & 12 & 12 & 12 & 11 & 10 & 10 & 7 & 8 & 8 & 12 & 3.4 & $80 \cdot 1$ \\
\hline 128 & 12 & 10 & 10 & 10 & 12 & 12 & 6 & 6 & 10 & 12 & 4.8 & $82 \cdot 1$ \\
\hline 129 & 19 & 10 & 15 & 5 & 5 & 16 & 2 & 5 & 7 & 17 & $33 \cdot 9 * * *$ & $43 \cdot 1$ \\
\hline 130 & 23 & 1 & 11 & 11 & 15 & 4 & 15 & 15 & 1 & 5 & $46.9 * * *$ & $40 \cdot 0$ \\
\hline 131 & 11 & 11 & 12 & 9 & 9 & 12 & 10 & 7 & 10 & 10 & $2 \cdot 1$ & 83.6 \\
\hline \multirow[t]{2}{*}{132} & 12 & 12 & 12 & 10 & 9 & 10 & 5 & 8 & 11 & 12 & 4.7 & $75 \cdot 5$ \\
\hline & & & & & & & & & & & & Mean $=63.2$ \\
\hline
\end{tabular}

$\chi^{2}=\mathrm{S}(\mathrm{O}-\mathrm{E})^{2}$, where $\mathrm{O}=$ observed weight, $\mathrm{E}=$ expected weight $(10$ for all cues).

$\bar{x}=$ Mean of original (untransformed) score on $100 \mathrm{~mm}$ scale.

* $P<0.05 ; * * P<0.01 ; * * P<0.001$. 
Table 4. Actual relative $\beta$-weights $\left(\times 10^{-2}\right)$, multiple regression coefficients $(R)$ and correlations between replicates $(r)$

\begin{tabular}{|c|c|c|c|c|c|c|c|c|c|c|c|c|c|}
\hline \multirow[b]{2}{*}{ Psychiatrist } & \multicolumn{10}{|c|}{ Cue } & \multirow[b]{2}{*}{$\chi^{2}$} & \multirow[b]{2}{*}{$R$} & \multirow[b]{2}{*}{$r$} \\
\hline & 1 & 2 & 3 & 4 & 5 & 6 & 7 & 8 & 9 & 10 & & & \\
\hline 101 & 22 & 12 & 26 & 3 & -1 & 12 & 6 & 9 & 6 & -3 & $78 \cdot 0$ & 0.88 & 0.99 \\
\hline 102 & 20 & 12 & 17 & 11 & 4 & 7 & -5 & 5 & 8 & 11 & 45.4 & 0.82 & 0.96 \\
\hline 103 & 25 & 19 & 17 & 13 & 2 & -2 & -3 & 4 & 5 & 10 & $80 \cdot 2$ & 0.90 & 0.99 \\
\hline 104 & 17 & 9 & 27 & 31 & 12 & -1 & 3 & 0 & 1 & 0 & $123 \cdot 5$ & 0.88 & 0.98 \\
\hline 105 & 9 & 10 & 11 & 9 & 10 & 10 & 11 & 10 & 11 & 10 & 0.5 & 1.00 & $1 \cdot 00$ \\
\hline 106 & 24 & 14 & 16 & 5 & 9 & 6 & 3 & -1 & 12 & 11 & 46.5 & 0.94 & 0.99 \\
\hline 107 & 12 & 14 & 23 & 8 & 6 & 13 & 4 & 10 & 6 & 3 & $31 \cdot 9$ & 0.85 & 0.99 \\
\hline 108 & 14 & 18 & 10 & 17 & -5 & 10 & 7 & -2 & -8 & -9 & $119 \cdot 2$ & 0.81 & 0.95 \\
\hline 109 & 7 & 19 & 30 & 2 & -8 & 8 & 7 & 1 & -2 & 16 & 115.2 & 0.86 & 0.96 \\
\hline 110 & 17 & 19 & 8 & 8 & -3 & 25 & 1 & 9 & 3 & -8 & 98.7 & 0.83 & 0.99 \\
\hline 111 & 40 & 5 & 11 & -4 & 7 & 2 & 0 & 10 & 9 & 11 & 129.7 & 0.95 & 099 \\
\hline 112 & 37 & 7 & 11 & -3 & 16 & 11 & 5 & 0 & 4 & 6 & $112 \cdot 2$ & 0.95 & 0.99 \\
\hline 113 & 15 & 17 & 24 & 8 & 11 & 9 & 6 & 3 & 5 & -1 & 48.7 & 0.94 & 0.99 \\
\hline 114 & 13 & 11 & 5 & 4 & 4 & 5 & -3 & 6 & 11 & 38 & $110 \cdot 2$ & 071 & 085 \\
\hline 115 & 43 & 19 & -3 & 0 & -9 & 12 & -1 & 0 & -4 & -10 & 262.1 & 0.86 & 0.98 \\
\hline 116 & 25 & 1 & 17 & 12 & 1 & 3 & 0 & 10 & 7 & 23 & 76.7 & 0.82 & 0.98 \\
\hline 117 & 28 & 10 & 4 & 2 & 27 & 10 & 13 & 4 & 0 & 3 & $90 \cdot 7$ & 0.91 & 097 \\
\hline 118 & 20 & 29 & -1 & 16 & 4 & 9 & 10 & -6 & 3 & -2 & 110.4 & 0.85 & 0.98 \\
\hline 120 & 32 & 11 & 25 & 10 & 4 & -5 & -2 & 0 & 3 & 7 & $145 \cdot 3$ & 0.94 & 0.97 \\
\hline 122 & 36 & 12 & 21 & -6 & 5 & 1 & 2 & 2 & 11 & 5 & $131 \cdot 7$ & 0.93 & 0.99 \\
\hline 124 & 22 & 26 & 20 & 1 & 3 & -1 & -3 & 8 & 9 & 7 & 105.4 & 0.83 & 0.97 \\
\hline 126 & 42 & 19 & 3 & -1 & -1 & 9 & 2 & 9 & 3 & 10 & $151 \cdot 1$ & 0.88 & 094 \\
\hline 127 & 43 & 12 & 20 & 2 & 6 & 2 & 0 & 2 & 8 & -6 & $176 \cdot 1$ & 0.95 & 0.98 \\
\hline 128 & 22 & 12 & 19 & 9 & 8 & 19 & 3 & 2 & 3 & 2 & $54 \cdot 1$ & 0.92 & 0.98 \\
\hline 129 & 50 & 2 & 15 & -6 & 5 & 9 & 3 & -6 & -1 & -2 & $254 \cdot 1$ & 093 & 0.98 \\
\hline 130 & 55 & 3 & -6 & -2 & -7 & 9 & 0 & -3 & -9 & -7 & $368 \cdot 3$ & 0.84 & 0.83 \\
\hline 131 & 11 & 12 & 43 & -2 & 1 & -4 & 9 & -1 & 8 & 8 & $164 \cdot 5$ & 0.86 & 0.98 \\
\hline 132 & 32 & 17 & 13 & 12 & 4 & 3 & 1 & 6 & 11 & -1 & $85 \cdot 0$ & 0.91 & 0.99 \\
\hline
\end{tabular}

$x^{2}=$ see Table 3.

$P<0.001$ for all except No. 105 .

showed considerable variation within as well as between judges. The squared multiple regression coefficients $\left(R^{2}\right)$ estimate the consistency with which each applied his or her judgemental policy. An $R$ of 0.8 or higher $\left(R^{2} \geqslant 0.64\right)$ indicates that at least $64 \%$ of the judgemental variation was satisfactorily accounted for by the linear and additive regression model. The correlation between replicates $(r)$ suggests the extent to which inconsistency within the observer may be responsible for such deficiencies as are observed in the model. Nos. 114 and 130 differed to the most marked degree from equality. Weights of 20 or more were awarded on 35 occasions, 25 judges doing so at least once. The average mean rank order of the actual $\beta$-weights correlated significantly with that of the specified weights (rho $=+0.703 ; 0.05>P>0.01$ ).

Items 1-3 (see Fig. 1) were most heavily weighted by almost half the judges, although not necessarily in that order; 6 other items were judges of first or second importance by at least one psychiatrist. Items 7, 8 and 9 (Fig. 1) only once received a weight of as much as $13 \%$, a value that can probably be attributed to chance. All negative weights (which never exceeded $10 \%$ ) can also be neglected, since the scoring of each item was arranged to show a positive association with depression. $R$ and $r$ were, with one exception, high $(>0.8)$, indicating that the rectilinear regression probably accounted satisfactorily for most of the variance in the individual judgements. The relatively low replicate reliability $(r=0.85)$ of No. 114 suggested that the poor fit of the model $\left(R=0.71, R^{2}=0.504\right)$ was due to some unreliability of judgement.

\section{The clinical trial}

The conventional results of the clinical trial have previously been presented in terms of the Hamilton Depression Rating Scale (HDRS) (Bech, 1984). In the present study, investigators' 


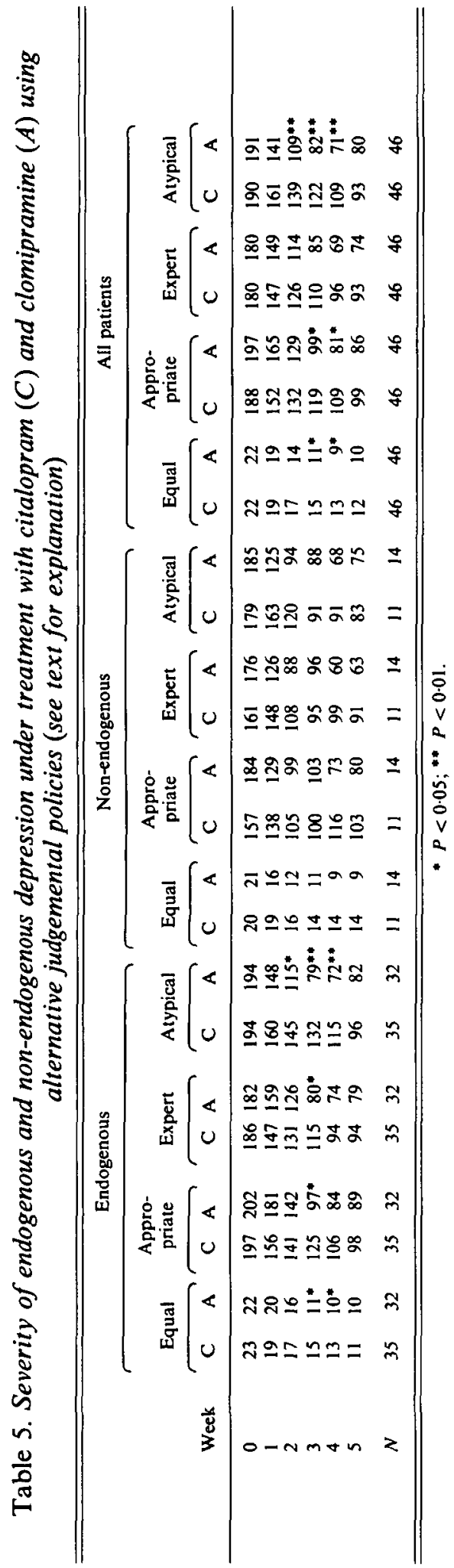

policies were obtained from their weighting of the MES items, and the description of the results that follows also differs in some other respects from that of Bech (1984).

Results from 46 patients on each treatment were available for this analysis. The two groups were broadly comparable in sex ratio, age distribution, duration of illness and current episode, and diagnosis by the Newcastle 1965 and 1971 Scales and DSM-III. Sixty-five and 67 respectively were diagnosed with the aid of the two Newcastle Scales as suffering from endogenous and either 27 or 25 from non-endogenous depression. The number of patients seen by the 15 participating physicians varied from 1 to 17 , with a median of 6 . Such a distribution is by no means atypical for trials with many investigators.

\section{Application of different judgemental policies to clinical trial observations}

Reasons for the choice of the actual judgement policies applied to the MES scores of the 92 patients in the clinical trial are considered in the Discussion. Four were chosen (Table 5): first, the equal weights policy (which left the raw scores unchanged); secondly, the policy of the appropriate psychiatrist - i.e. the one who had seen the patient on the occasion in question; thirdly, an 'expert' policy (see section on 'Psychiatrists', above); fourthly, that of a single representative of the group (No. 104), atypical in that he gave a particularly high weight to cue 4 (the sleep item of the MES). These are referred to in the column headings of Table 5 as 'Equal', 'Appropriate', 'Expert' and 'Atypical', respectively.

For the 'Equal' weight policy, statistically significant differences between treatments $(P<0.05)$ were apparent at weeks 3 and 4 for the endogenous group as well as for the patients as a whole. No significant differences appeared at any time in the smaller group with the diagnosis of non-endogenous depression.

There are striking contrasts between the results of applying the other policies. None gave rise to significant differences in the nonendogenous group; but, whereas the 'Appropriate' policy scored one fewer significant difference than that of 'Equal' (endogenous at week 4), application of the 'Expert' policy lost 3 of the 4 (endogenous at week 4 and all patients at weeks 3 and 4). However, not only did the 
'Atypical' policy give rise to 2 additional significant differences (at week 2 in the endogenous and all patient groups), but 5 of the 6 differences were significant at $P<0.01$, a level not attained by any policy on any occasion. Thus, with the use of this policy, differences between treatments appeared earlier and reached greater levels of statistical significance.

\section{DISCUSSION}

An assumption almost always made in clinical trials involving more than one investigator is that the judgements of all investigators, or at least of those within a given centre, can be treated as equivalent, whether or not inter-observer agreement has been measured and whether or not this turns out to be 'satisfactory'. If the degree of agreement is considered to be 'unsatisfactory', training to reduce the differences may be carried out. But, even if measures of inter-observer agreement are made (e.g. in terms of the kappa statistic), they do not lend themselves to improvements in the sensitivity of the trial.

Judgement Analysis, however, makes explicit the reasons for the differences observed, and the resulting information may be used in several ways: first, knowledge and use of actual individual policies enables their owners to carry out their intentions more accurately - the computed policy can be adjusted if necessary and then applied with complete consistency; secondly, shared knowledge of policy differences can accelerate mutual agreement and the development of consensus; thirdly, a 'best' policy, derived from consensus, authority or in some other way can be applied to the judgements of all.

If investigators in a clinical trial, especially those working in different centres, do not even observe the same patients, it is surely even more important to bring their judgements into a common frame of reference. By this means, within- and between-observer variation can be removed from the error variance. The power of the design is thereby increased; and, in consequence, the likelihood of committing a Type $2 \mathrm{Er}$ ror (Stewart et al. 1975; Joyce, 1984) will be decreased. Alternatively, the sample size can be reduced - a choice that is always defensible on ethical (Montgomery \& Åsberg, 1979) as well as usually on economic grounds.

The present study was intended to test the prediction that the application of one or more judgement policies, rendered consistent by the removal of unreliability, to the assessment made in a real-life clinical trial would improve its specificity. Any, or all, or some combination, of the policies available might have been used. One psychiatrist used an equal weights policy; many others resembled each other. There would have been no point in testing all of them. In the event, it seemed rational to apply the policy of the 'Appropriate' psychiatrists to the observations on the patients for whom they were responsible. An 'Expert' policy was also chosen, for obvious reasons. The 'Atypical' policy was chosen because it gave a particularly high weight to an MES item otherwise seldom selected; except for several policies that, like the 'Expert' policy, gave very high weights to one or other of the first three cues, it departed most widely from one of equal weights.

Although none of the three examples tested affected the judgements of severity in patients with non-endogenous depression to the point where the differences between treatments became statistically significant, the 'Atypical' policy improved the discrimination between treatments in most of the time/diagnosis cells for endogenous patients and for the group as a whole (Table 5), usually increasing the level of statistical significance. On the other hand, the use of the 'Appropriate' and 'Expert' policies reduced the discriminations below those achieved by the use of 'Equal' weights. Untransformed (i.e. equally weighted) scores are frequently used by those who employ rating scales, although this is not the case in, for example, the Hamilton Depression Scale (HDS) where the range of possible scores is not the same for all items. However, even if the weights are not entirely arbitrary, they are seldom submitted to sensitivity analysis. Judgement Analysis in effect does this and so provides a rational or at least an explicit basis for weight selection.

As the use of Judgement Analysis to decrease error variance increases the sensitivity of the trial design, another obvious explanation for the failure of the 'Atypical' policy to establish any significant treatment difference in the nonendogenous group is that there was no real difference between the two treatments for such patients. Both drugs in the trial acted on endogenous and non-endogenous depression, 
clomipramine producing a significantly faster change than citalopram on total HDS score (Bech, 1984). However, when the sleep item was omitted, as in the Bech et al. (1975) sub-scale of the HDS, the difference between the two treatment groups became less pronounced. (The group of 5-HT uptake inhibitors, to which citalopram belongs, seems in general to have little effect on sleep disturbances during the early weeks of treatment (d'Elia et al. 1981).) Although other evidence suggests that clomipramine is effective in non-endogenous depression (Rack, 1973), no studies with citalopram have been published so far, so the choice between these explanations is not clear.

Surprisingly, neither the 'Appropriate' nor the 'Expert' policies improved on 'Equal' weights. The 'Appropriate' policy was really less appropriate than its title indicates: in spite of considerable efforts to ensure that individual patients were seen by the same psychiatrist, this was often not possible in practice. On such occasions, the policy of the intended rather than of the actual psychiatrist was used in the analysis. The relative failure of the 'Expert' policy is harder to explain, given the success of the 'Atypical' policy. However, the failure of the 'Expert' policy was only relative. It led to a better discrimination of the treatments than did the 'Appropriate' policy on 12 of the 15 possible comparisons, 4 occurring in the non-endogenous group.

Other procedures would have been possible. For example, policies based on mean or modal weights could have been used. These would probably have given rise to policies similar to those based on equal weights, and therefore results resembling those obtained in the traditional way. A number of studies (e.g. Deane et al. 1972; Kirwan et al. 1983c) suggest that the optimal procedure is to use the 'captured' individual policies to provide feed-back to the participants about their judgemental processes and so facilitate the development of an informed consensual policy. This was not attempted, but is planned for a future study.

Progress can also be made in the improvement of observation by using standardized simulated video performances (Russell et al. 1983); for example, by having the MES scores of 10 patients enacted and videotaped. This establishes control over the observational, as distinct from the judgemental, task by creating external criteria; and its use therefore deserves closer study in psychiatric training. No doubt because the scores were, in effect, twice transformed (by the actors and the members of the audience), the resulting judgements of severity did not agree very closely with those on the cases to which they corresponded $(r=0.62, P<0.05$ : Table 2$)$; the ratings on the 10 individual scale items were in better agreement $(r=0.78, P<0.01$ : Table 2$)$. Customary methods (e.g. Tiplady \& Loudon, 1980) do not separate observation and judgement and so do not make explicit the causes of disagreement.

The results of analysis of actual judgements were very similar, both in the general distribution of weights and as to the levels of consistency and reliability achieved, to those found by Fisch et al. $(1981,1982)$ with general physicians and psychiatrists in Switzerland, by Joyce et al. (1977) and by Kirwan and his colleagues with rheumatologists in the United Kingdom (Kirwan et al. $1983 a, b, c, 1984)$. Although, as expected, there were wide differences in the policies of individual judges, as well as between the policies they believed themselves to be using and the actual policies elicited from their judgements about simulated patients, the rectilinear multiple regression model fitted the actual policies of most individuals very closely. The equal weights model did not (with the exception of that of No. 105), although, when asked to specify their policies, the majority of judges also expressed weights that tended to equality. This is noteworthy, because the assumption is very often tacitly made in the construction of rating scales that all items contribute equally to the total. In clinical trials, too, the global evaluation of treatment, if defined at all, often seems to represent the total of individual items that are equally weighted, but not explicitly so.

The disparity between specified and actual policies illuminates current conflicts of opinion about rating scales in clinical psychiatry. Asked to estimate the weights they attributed to the items of the MES, most psychiatrists (19/28) specified a policy of weights that were close to equal (i.e. corresponding to traditional ratingscale practice); their behaviour in a task corresponding more closely to clinical practice, however, was quite different. Here, the use of an equal weights policy was exceptional $(1 / 28)$. 
The high average mark ( $\bar{x}$ : Table 3 ) placed on the 10 analogue scales during weight specification presumably indicated that the items in the MES scale were considered by most psychiatrists to be relevant to the assessment of severity of depression - a low mean weight would have suggested that some items at least were considered to be irrelevant. It seems that giving the scale items of the MES equal weights 'feels' unsatisfactory. The feeling may be correct; it is evidently possible to obtain a more specific measure of the severity of depression than that given by traditional scoring by weighting the items according to other considerations. In the absence of an external criterion for assessment, it may be objected that it is not possible to decide which method has the highest validity. This situation is, of course, typical in psychiatry, where, as elsewhere, the type of validity in question often also lacks definition. In the present case, however, it has been demonstrated that the application of Judgement Analysis to a clinical trial can improve the power of the trial design to discriminate between treatments. On the other hand, the use of trials to study clinical judgement provides a rational criterion for choosing between alternative ways of estimating the severity of illness.

\section{CONCLUSIONS}

Twenty-eight Danish psychiatrists, 15 of whom were participants in a subsequent clinical trial, first specified the relative importance they attached to each item of the Melancholia Scale (MES) in assessing the severity of depression. Their actual behaviour in judging depression was examined by multiple regression analysis of their evaluation of 50 simulated cases. Largedifferences were found between individuals' specified and actual judgemental policies, and between the actual policies of individuals, although most of the latter were applied with high consistency.

Such variations impair the accuracy of a clinical trial. Judgement Analysis allows a policy to be developed that can be applied to all judgements. The prediction that the removal of important sources of error variance by this means would reduce the likelihood of committing a Type 2 Error was supported by the application of actual policies to observations made in a clinical trial of 2 antidepressive treatments, in which the significance of differences in their effects on the severity of depression was increased and appeared earlier.

The MES profiles of 10 cases were also converted into narrative case histories enacted by experienced psychiatrists or psychologists and videotaped. The participants scored the items of the MES scale for these videocases and judged the overall severity of the depression. These judgements were in good agreement with those for the original patients. Thus, patients with quantitatively defined characteristics were satisfactorily simulated by this method. Videotapes so prepared can help to reduce variation in observation, just as Judgement Analysis can lead to reductions in the variation of judgement.

Kurt Jacobsen, Jan Trøst and Bodil Winter of Ciba-Geigy (Denmark) gave invaluable administrative and clerical assistance. Statistical advice and/or computing assistance was kindly given by Max Stubgaard (Frederiksborg Amt Centralsygehus, Hillerød), Peter Allerup (Danish Institute of Educational Research), Ove Aaskoven (Lundbeck) and Claus Bech. Teresa Harnisch, Sonja T. Pedersen and Rosemary Szente efficiently and patiently typed the several drafts. Several colleagues, notably Hans-Ueli Fisch, provided valuable criticism.

\section{APPENDIX}

\section{Narrative for Simulated Case No. 14}

The patient was hospitalized a week ago after an attempted suicide. The interviewer begins by focusing on his experience of the previous 3 days.

The patient communicates a lowered mood, has no interest in usual activities, feels sad and miserable, nothing in the surroundings can excite him. During the interview he gives non-verbal signs of depression, is expressionless, 'greyish'. There are still suicidal impulses. There is no feeling of guilt. During the last 3 nights there has been some difficulty in falling asleep (1- $1 \frac{1}{2}$ hours) but the sleep length is only slightly reduced. In the ward the patient has not been able to participate in the daily activities. He shows no need or ability to contact other patients or ward personnel, even the person especially charged with watching the patient due to the risk of suicide. He feels emotionally indifferent, even to near friends or his family. He experiences an unpleasant state of anxiety or fear without apparent reason, a vague and uneasy feeling which he can, however, just control. Hence, there have been no panic attacks.

The patient is unable to relax, feels tensed up and becomes tired easily. He has less energy than usual and 
there are sometimes painful sensations in his back, but no real pains. He has difficulties in concentrating; it is more difficult for him than usual to read a book or even a newspaper. During the interview, however, there are no signs of difficulties in concentration.

\section{REFERENCES}

Bartko, J. J. \& Carpenter, W. T. (1976). On the methods and theory of reliability. Journal of Nervous and Mental Disease 163, 307-317

Bech, P. (1981). Rating scales for affective disorders: their validity and consistency. Acta Psychiatrica Scandinavica 64, Suppl. 295, 1-101.

Bech, P. (1984). Citalopram versus clomipramine: a controlled clinical study. Clinical Neuropharmacology 7, Suppl. 1, 5471-5472.

Bech, P. \& Rafaelson, O. J. (1980). The use of rating scales exemplified by a comparison of the Hamilton and the BechRafaelsen Melancholia Scale. Acta Psychiatrica Scandinavica 62, Suppl. 285, 128-132.

Bech, P., Gram, L. F., Dein, E., Jacobsen, O., Vitger, J, \& Bolwig, T. G. (1975). Quantitative rating of depressive states. Acta Psychiatrica Scandinavica 51, 161-170

Bech, P., Gjerris, A., Andersen, J., Bøjholm, S., Kramp, P., Bolwig, T. G., Kastrup, M., Clemmesen, L. \& Rafaelsen, O. J. (1983). The Melancholia Scale and the Newcastle Scales. Item-combinations and inter-observer reliability. British Journal of Psychiatry 143, 5863.

Cronholm, B. \& Ottosson, J.-O. (1960). Experimental studies of the therapeutic action of electroconvulsive therapy in endogenous depression. The role of the electrical stimulation and of the seizure studied by variation of stimulus and modification by lidocaine of seizure discharge. Acta Psychiatrica Neurologica Scandinavica Suppl. 145, 69--97.

Deane, D. H., Hammond, K. R. \& Summers, D. A. (1972). Acquisition and application of knowledge in complex inference tasks. Journal of ExperimentaL Rsychology 92, 20-26.

d'Elia, G., Hällström, T., Nyström, C. \& Ottosson, J.-O. (1981) Zimelidine versus maprotiline in depressed outpatients. A preliminary report. Acta Psychiatrica Scandinavica 63, Suppl. 290. 225-235.

Fisch, H.-U., Hammond, K. R., Joyce, C. R. B. \& O'Reilly, M. (1981). An experimental study of the clinical judgment of general physicians in evaluating and prescribing for depression. British Journal of Psychiatry 138, 100-109.

Fisch, H.-U., Hammond, K. R. \& Joyce, C. R. B. (1982). On evaluating the severity of depression: an experimental study of psychiatrists. British Journal of Psychiatry 140, 378-383.

Freiman, J. A., Chalmers, T. C., Smith, H. J. \& Kuebler, R. R. (1978). The importance of $\beta$, the type II error and sample size in the design and interpretation of the randomized control trial: survey of 71 'negative' trials. New England Journal of Medicine 299, $690-694$.

Hamilton, M. (1960). A rating scale for depression. Journal of Neurology, Neurosurgery and Psychiatry 23, 56-62.
Hammond, K. R. (1975). Social Judgment theory: its use in the study of psychoactive drugs. In Psychoactive Drugs and Social Judgment (ed. K. R. Hammond and C. R. B Joyce), pp. 69-105. Wiley Interscience: New York.

Hammond, K. R., Stewart, T. R., Brehmer, B. \& Steinmann, D. O. (1975). Social Judgment Theory. In Human Judgment and Decision Processes (ed. M. F. Kaplan and S. Schwartz), pp. 271-312. Academic Press: New York.

Joyce, C. R. B. (1984). Judgment analysis and clinical trials. How to save the baby from the bathwater. Controlled Clinical Trials $\mathbf{5}$, 307-308.

Joyce, C. R. B., Berry, H., Chaput De Saintonge, D. M., Domenet, J., Fowler, P. \& Mason, R. M. (1977). Judgment analysis of investigators' assessments: a way to reduce one important source of error in multi-centre trials. In International Co-ordination of Drug Trials (ed. K. Fehr, E. C. Huskisson and E. Wilhelmı). Eular Bulletin Monograph No. 1.

Kirwan, J. R., Chaput de Saintonge, D. M., Joyce, C. R. B. \& Currey, H. L. F. (1983a). Clinical judgement in rheumatoid arthritis. I. Rheumatologists' opınions and the development of 'paper patients'. Annals of the Rheumatic Disease 42, 644-647.

Kirwan, J. R., Chaput de Saintonge, D. M., Joyce, C. R. B. \& Currey, H. L. F. $(1983 b)$. Clinical judgement in rheumatoid arthritis. II. Judging 'current disease activity' in clinical practice. Annals of the Rheumatic Diseases 42, 648-651.

Kirwan, J. R., Chaput de Saintonge, D. M., Joyce, C. R. B. \& Currey, H. L. F. (1983c). Clinical judgment analysis - practical application in rheumatoid arthritis. British Journal of Rheumatology 22, (Suppl.), 18-23.

Kirwan, J. R., Chaput de Saintonge, D. M., Joyce, C. R. B. \& Currey, H. L. F. (1984). Clinical judgement in rheumatoid arthritis. III. British rheumatologists' judgments of 'change in response to therapy'. Annals of the Rheumatic Diseases 43, 686-694.

Mainland, D. (1963). Elementary Medical Statistics. W. B. Saunders: Philadelphia.

Montgomery, S. A. \& Åsberg, M. (1979). A new depression scale designed to be sensitive to change. British Journal of Psychiatry 134, 382-389.

Rack, P. H. (1973). A comparative clinical trial of oral clomipramine (Anafranil) against imipramine. Journal of International Medical Research 1, 332-337.

Russell, M. L., Ghee, K. L., Probstfield, J. L. \& Insull, W. (1983). Development of standardized simulated patients for quality control of the clinical interview. Controlled Clinical Trials 4, 197-208.

Stewart, T. R., Joyce, C. R. B. \& Lindell, M. K. (1975), New analyses: application of judgment theory to physicians' judgments of drug effects. In Psychoactive Drugs and Social Judgment (ed. K. R. Hammond and C. R. B. Joyce), pp. 249-262. Wiley Interscience: New York.

Tiplady, B. \& Loudon, J. B. (1980). Assessment of depression and the non-psychiatrist. In Abstracts of the 12th CINP Congress, 340. Pergamon: Oxford.

Vere, D. W. (1984). Logic and valid inference. In Current Problems in Clinical Trials (ed. D. M. Chaput de Saintonge and D. W. Vere), pp. 35-40. Blackwell: Oxford. 